\title{
EL PAPEL DE LOS ACTORES SOCIALES EN TIEMPOS DE CRISIS
}

\author{
THE ROLE OF SOCIAL ACTORS IN TIMES OF CRISIS
}

\author{
Iván Medina Iborra \\ Universidad Autónoma, Madrid. España/Spain \\ ivan.medina.iborra@gmail.com \\ Joaquim M. Molins \\ Universidad Autónoma, Barcelona. España/Spain \\ joaquim.molins@uab.cat \\ Carmen Navarro Gómez \\ Universidad Autónoma, Madrid. España/Spain \\ c.navarro@uam.es
}

Recibido/Received: 15/12/2012

Aceptado/Accepted: 27/02/2013

\section{RESUMEN}

El objetivo de este artículo es analizar el desempeño de los dos sindicatos mayoritarios (UGT y CCOO) y de la patronal CEOE durante la crisis económica. Se propone un análisis centrado en su posición frente a las principales reformas, las diferencias ideológicas sobre diversas políticas públicas y su capacidad para negociar acuerdos sobre negociación colectiva. Recurrimos a la Constitución Española de 1978, que en su séptimo artículo otorga un papel destacado a sindicatos y asociaciones empresariales en la representación de intereses económicos y laborales, para considerar que los actores sociales disminuyen sus opciones de veto en tiempos de crisis económica dada la situación de excepcionalidad. No obstante, el artículo confirma un distanciamiento en los planteamientos de los actores sociales y las pocas opciones de un diálogo social firme. Esto conduce a un mayor distanciamiento entre los actores sociales y la opinión pública como demuestran los resultados derivados de la encuesta sobre "Cultura y Representación Política en España".

PALABRAS CLAVE

UGT, CCOO, CEOE, políticas públicas, opinión pública, diálogo social.

\section{SUMARIO}

1. Introducción. 2. El grado de apoyo de los actores sociales a las reformas económicas. 3. El posicionamiento público de los actores sociales frente a los temas de la agenda pública. 4. La capacidad de los actores sociales para lograr acuerdos. 5. La valoración ciudadana del papel de los actores sociales en la actual crisis. 6. Conclusiones. Bibliografía.

\section{ABSTRACT}

The aim of this article is to analyze the performance of the two main trade unions (UGT and CCOO) and the employers' association CEOE during the economic crisis. The analysis focuses on their position on major reforms, on their ideological differences over various public policies, as well as on their ability to negotiate collective bargaining agreements. We depart from the command of the Spanish Constitution of 1978, which in its seventh article gives trade unions and business associations a 
prominent role in representing economic interests, to suggest that social actors would be likely to reduce their chances of veto in times of economic crisis given the exceptional situation. However, the article confirms a gap in the approaches of social actors and the few options for a strong social dialogue. This leads to a greater distance between the social actors and the public opinion, as evidenced by the results derived from the survey on 'Culture and Political Representation in Spain'.

\section{KEYWORDS}

UGT, CCOO, CEOE, public policies, public opinion, social dialogue.

\section{CONTENTS}

1. Introduction. 2. The degree of support from the social actors to the economic reforms. 3 . The public positioning of the social actors on the issues of the public agenda. 4. The ability of social actors to reach agreements. 5. The public assessment of the role of social actors in the current crisis. 6. Conclusions. References.

\section{INTRODUCCIÓN}

Este artículo analiza el comportamiento de la patronal CEOE y de los sindicatos UGT y CCOO durante la crisis económica en España, iniciada en 2008, y, especialmente, en su posición respecto a los principales temas de la agenda pública. Por un lado, nos interesa conocer sus estrategias y sus planteamientos ideológicos. Además se examina su capacidad de llegar a acuerdos en materia de negociación colectiva. Estudios previos han considerado que empresarios y sindicatos han desempeñado un papel de enorme peso en los procesos de transición económica como fue la Unión Monetaria y Económica (Hancké y Rhodes, 2005). Esta tendencia hacia el tripartismo sigue siendo una opción en la actualidad (Natali y Pochet, 2010). Aunque algunos estudios responsabilizan a los gobiernos y las presiones electorales de los avances en la concertación social (Hamann y Kelly, 2011), no debemos pasar por alto la raison d'être de los actores sociales como intermediarios de intereses sociales sectoriales y su capacidad para plantear estrategias y dinámicas de negociación (Hassel, 2008). Aceptamos, sin embargo, que la capacidad de gobiernos y actores sociales para acometer todos los retos exigibles es menguante (Schmitter, 2008), en un escenario institucional cambiante (Brandl y Traxler, 2011) donde la tensión entre partidos políticos y actores sociales se apresura a interrumpir el consenso en el diálogo social (Natali y Pochet, 2009). En esta relación de intercambio, algunos autores consideran simplemente que los gobiernos acceden al diálogo social para compensar los posibles efectos negativos de un sindicalismo extremadamente movilizado (Acocella y Di Bartolomeo, 2011). Como apuntara Siegel (2005), la verdad es que el diálogo social no aporta eficiencia al resultado sino que es un componente del proceso. El caso español es paradigmático en este punto ya que en la mayoría de ocasiones el diálogo social tripartito ha sido un instrumento gubernamental para alcanzar retos político-económicos (Molina y Rhodes, 2011) con unos resultados más bien pobres y una institucionalización incoherente (Advagic, et al. 2011). A cambio a los actores sociales se les ha garantizado autonomía respecto al gobierno (Royo, 2007), esto es, se les ha garantizado una mayor representación institucional alejada de la influencia política (Novell, et al. 2011), aspecto con efectos negativos en la capacidad de confrontación (Friot, 2004) y en las bases de representación y legitimidad social (Arasanz y López Martí, 2005). No 
obstante, la tradición en este asunto fija que en España la concertación social sea variada, habitualmente centralizada y no institucionalizada (Nonell, 1987).

¿Qué actitud muestran actualmente los actores sociales? ¿Han iniciado un periodo de colaboración como en crisis pasadas? Teniendo en cuenta la enorme influencia del path dependency en las cuestiones relacionadas a las negociaciones entre actores sociales (véase Howell y Givan, 2011), y el ejemplo los esfuerzos para la incorporación de España a la Unión Monetaria, se espera que la CEOE, UGT y CCOO hayan sido capaces de acercar posiciones y contribuir a la concertación social en los últimos años. El artículo se estructura de la siguiente manera: la siguiente sección analiza la postura de la CEOE, UGT y CCOO frente a las principales reformas acometidas por los gobiernos de Zapatero y Rajoy desde el 2008. La sección tercera se dedica a la descripción ideológica de los actores sociales frente a siete políticas públicas con tal de analizar el grado de proximidad entre sus planteamientos. La cuarta sección se ocupa de la capacidad de negociación de los actores sociales al margen del gobierno. Se toma como ejemplo los procesos de negociación de convenios colectivos. Finalmente se analiza la opinión pública frente a papel de los actores sociales en la crisis económica. Esto servirá para valorar la afirmación de que patronal y sindicatos se han alejado de sus bases sociales por efecto de su institucionalización.

\section{EL GRADO DE APOYO DE LOS ACTORES SOCIALES A LAS REFORMAS ECONÓMICAS}

En esta sección se analizan el grado de apoyo de la CEOE, la UGT y CCOO a las principales reformas gubernamentales emprendidas desde el 2008 hasta mediados del año 2012. Este periodo comprende gobiernos socialista, presidido por José Luis Rodríguez Zapatero, y popular, encabezado por Mariano Rajoy. La forma más eficaz de proceder con el análisis es considerar mayoritariamente respuestas dicotómicas de apoyo o rechazo, solamente alterado cuando una matización sea cualitativamente oportuna. En muchas ocasiones las comunicaciones de la patronal y los sindicatos no son muy extensas en detalles, especialmente cuando tienen una visión favorable. En otras ocasiones no existe una respuesta al anuncio de reformas, aspecto que se tendrá también en cuenta. De una u otra forma, detrás de las respuestas -o el silencio- de los actores sociales a las medidas del Gobierno se observan dos claras consecuencias: por un lado, el actor manifiesta su grado de satisfacción con la política pública y lanza un determinado mensaje a sus miembros y a la opinión pública y, por otro lado, si una actitud de apoyo es sostenida en el tiempo se puede considerar que existe una fuerte relación entre los intereses del actor y las políticas del gobierno o todo lo contrario si se observa un rechazo constante. En nuestro caso, lo más interesante aquí será comentar el segundo tipo de consecuencias. Por lo referente a la primera consecuencia, en la sección quinta se examinan los asuntos relacionados con la opinión pública y los actores sociales en España de forma global.

Puesto que la actividad gubernamental y normativa de un Gobierno es vasta, el criterio de selección de las reformas está condicionado por el argumento expreso por parte del gobierno de que dicha reforma -o paquete de reformas- está provocada por, o quiere resolver, aspectos de la crisis económica. Por lo general estas reformas se refieren al sistema bancario, el mercado laboral, el gasto en políticas sociales y el gasto de la administración pública. La formalidad en las respuestas de los actores sociales es variable. 
Tabla 1. Reformas planteadas por el Gobierno de Zapatero (2008-2011)

\begin{tabular}{|c|c|c|c|c|c|c|}
\hline \multicolumn{4}{|c|}{ Características de las reformas } & \multicolumn{3}{|c|}{ Respuestas de los actores sociales } \\
\hline Fecha & Nombre & Objetivo & Principales medidas & CEOE & UGT & $\mathrm{CCOO}$ \\
\hline $\begin{array}{l}24 / 06 / \\
2008\end{array}$ & $\begin{array}{l}\text { Plan de } \\
\text { Austeridad }\end{array}$ & $\begin{array}{l}\text { Ahorro } 250 \\
\text { millones de } \\
\text { euros }\end{array}$ & $\begin{array}{l}\text { Reducción } 70 \% \text { oferta empleo } \\
\text { público } \\
\text { Reducción sueldo altos cargos }\end{array}$ & Apoyo & $\begin{array}{l}\text { Apoyo, pero } \\
\text { sugiere } \\
\text { diálogo social }\end{array}$ & $\begin{array}{l}\text { Apoyo, } \\
\text { sugiere } \\
\text { diálogo } \\
\text { social }\end{array}$ \\
\hline $\begin{array}{l}14 / 08 / \\
2008\end{array}$ & & $\begin{array}{l}\text { Estimular la } \\
\text { economía }\end{array}$ & $\begin{array}{l}\text { Disposición de } 20.000 \text { millones } \\
\text { de } € \text { en dos años } \\
\text { Reformas en vivienda, IVA, } \\
\text { pymes, energía. } \\
\text { Supresión impuesto patrimonio }\end{array}$ & Rechazo & Apoyo & Apoyo \\
\hline $\begin{array}{l}28 / 11 / \\
2008\end{array}$ & & $\begin{array}{l}\text { Creación } \\
300.000 \\
\text { trabajos en } \\
2009\end{array}$ & $\begin{array}{l}\text { Inversiones urgentes por } \\
11.000 \text { millones de } € \\
\text { (principalmente en obras } \\
\text { públicas municipales). } \\
\text { Ayudas a compra automóvil } \\
\text { Inversión en I+D, viviendas... }\end{array}$ & - & - & - \\
\hline $\begin{array}{l}12 / 01 / \\
2009\end{array}$ & PlanE & $\begin{array}{l}\text { Creación de } \\
\text { empleo y } \\
\text { estímulo de la } \\
\text { economía }\end{array}$ & $\begin{array}{l}\text { Reducción gasto corriente } \\
\text { AAPP }(2.500 \text { millones } €) \\
\text { Políticas de empleo }(3.000 \mathrm{~m} €) \\
\text { Ampliación fondos ICO } \\
(47.000 \mathrm{~m} €)\end{array}$ & - & - & - \\
\hline $\begin{array}{l}26 / 07 / \\
2009\end{array}$ & $\begin{array}{l}\text { RD sobre } \\
\text { reestructuración } \\
\text { bancaria }\end{array}$ & $\begin{array}{l}\text { Reforma } \\
\text { bancaria }\end{array}$ & $\begin{array}{l}\text { - Creación del FROB con } 9.000 \\
\text { millones de } €\end{array}$ & Apoyo & $\begin{array}{l}\text { Apoyo, pero } \\
\text { sugiere } \\
\text { diálogo social }\end{array}$ & $\begin{array}{l}\text { Apoyo, } \\
\text { sugiere } \\
\text { diálogo } \\
\text { social }\end{array}$ \\
\hline $\begin{array}{l}04 / 03 / \\
2010\end{array}$ & $\begin{array}{l}\text { Ley de } \\
\text { Economía } \\
\text { Sostenible }\end{array}$ & $\begin{array}{l}\text { Mejora de la } \\
\text { competitividad } \\
\text { de la economía } \\
\text { española }\end{array}$ & $\begin{array}{l}\text { - Reducción trámites } \\
\text { administrativos } \\
\text { - Inversiones en TIC, ciencia e } \\
\text { innovación }\end{array}$ & Rechazo & $\begin{array}{l}\text { Apoyo, pero } \\
\text { variarán su } \\
\text { posición } \\
\text { inicial hasta } \\
\text { rechazar la } \\
\text { propuesta }\end{array}$ & Rechazo \\
\hline $\begin{array}{l}01 / 07 / \\
2010\end{array}$ & Subida IVA & & $\begin{array}{l}\cdot \text { Aumento del tipo general del } \\
16 \text { al } 18 \% \\
\cdot \text { Aumento del tipo reducido } \\
\text { del } 7 \text { al } 8 \%\end{array}$ & Rechazo & Rechazo & Rechazo \\
\hline $\begin{array}{l}17 / 09 / \\
2010\end{array}$ & $\begin{array}{l}\text { Ley de } \\
\text { medidas } \\
\text { urgentes para } \\
\text { la reforma del } \\
\text { mercado } \\
\text { laboral }\end{array}$ & & $\begin{array}{l}\text { - Flexibilización convenios } \\
\text { colectivos } \\
\cdot \text { Penalización de los contratos } \\
\text { temporales } \\
\text { - Expansión de indemnización } \\
\text { de } 33 \text { por año trabajado en caso } \\
\text { de despido }\end{array}$ & Rechazo & $\begin{array}{l}\text { Rechazo } \\
\text { Huelga Genera } \\
(29 \text { septiembre }\end{array}$ & \\
\hline $\begin{array}{l}19 / 02 / \\
2011\end{array}$ & $\begin{array}{l}\text { R.D. para el } \\
\text { reforzamiento } \\
\text { del sistema } \\
\text { financiero } \\
\end{array}$ & & $\begin{array}{l}\text { Endurecimiento de los } \\
\text { requisitos de capitalización de } \\
\text { la banca }\end{array}$ & - & Rechazo & Rechazo \\
\hline $\begin{array}{l}01 / 08 / \\
2011\end{array}$ & $\begin{array}{l}\text { Ley de } \\
\text { Reforma de } \\
\text { las pensiones } \\
\end{array}$ & $\begin{array}{l}\text { Reforma de la } \\
\text { Seguridad } \\
\text { Social } \\
\end{array}$ & - Reforma requisitos & Apoyo & Apoyo & Aроуо \\
\hline $\begin{array}{l}26 / 08 / \\
2011\end{array}$ & $\begin{array}{l}\text { Reforma } \\
\text { constitucional }\end{array}$ & $\begin{array}{l}\text { Estabilidad } \\
\text { presupuestaria }\end{array}$ & $\begin{array}{l}\text { - Reforma art. } 135 \mathrm{CE} \\
\text { - Déficit máximo del } 0,4 \% \text { a } \\
\text { partir de } 2020\end{array}$ & Apoyo & Rechazo & Rechazo \\
\hline
\end{tabular}

Fuente: Elaboración propia 
En algunos casos es posible encontrar notas de prensa debidamente argumentadas y publicitadas, mientras que en muchos otros casos el posicionamiento público de las asociaciones corre a cuenta de algún líder que se refiere a la cuestión en declaraciones a medios de comunicación.

¿Cuál ha sido el comportamiento de los actores sociales durante la crisis económica en España? Las primeras reformas derivadas de la crisis las propone el expresidente Rodríguez Zapatero a mediados de Julio de 2008 como se puede observar en la Tabla 1. Serían las primeras medidas de austeridad de un presidente de Gobierno que había impulsado un buen número de políticas de bienestar en su pasado mandato y que encaraba su reelección con esquivas a la existencia de la crisis económica (Colino y Cotarelo, 2012). Los sindicatos y la patronal apoyaron el cambio de rumbo gubernamental aunque con diferentes argumentos. La CEOE se mostraba favorable a aplicar reformas de gran calado con la austeridad como eje principal. Los sindicatos aplaudían el reconocimiento de la crisis por parte del PSOE y encomendaban al Gobierno a abrir el diálogo social para trazar un plan de actuación. Si bien el primer anuncio de reformas pretendía una reducción del gasto, la siguiente tanda de reformas nacía de un espíritu keynesiano. Los sindicatos apoyaron el gasto público para estabilizar una tasa de desempleo creciente, pero la CEOE mostró rechazo. La actitud de la CEOE no cambiaría hasta mediados de 2011 con la salvedad de un apoyo a la primera reforma bancaria.

La reforma laboral de Septiembre de 2010 supuso la ruptura del apoyo sindical al Gobierno socialista. Anteriormente los sindicatos habían rechazado las reformas del IVA y de la Ley de Economía Sostenible. Si bien es cierto que la UGT fue más tímida que CCOO en este cambio de parecer. Posteriormente a la huelga general, los sindicatos sólo apoyaron la reforma del sistema de pensiones debido a que se consensuó mediante diálogo social y ellos eran responsables del resultado (Acuerdo Social y Económico para el crecimiento, el empleo y la garantía de las pensiones). De forma contraria, el presidente Zapatero encontró el apoyo de la CEOE en sus últimos meses en el Gobierno. La patronal apoyó la reforma constitucional para garantizar la estabilidad presupuestaria y celebró la definitiva apuesta por la austeridad en el gasto público.

La victoria electoral del Partido Popular aventuraba una ola de reformas de gran calado. A diferencia de la pasada legislatura, la CEOE ha mantenido una posición inalterable de apoyo a los anuncios de los populares. La gran mayoría de reformas sugieren austeridad en el gasto a la vez que un nuevo diseño del modelo de políticas públicas y estructuras de negociación. Como se observa en la Tabla 2 la reforma de las administraciones públicas ha centrado gran parte de los esfuerzos del Gobierno popular. En los otros casos se han acometido reformas bancarias, reducción del gasto destinado a políticas públicas y modificaciones legales. Uno de los cambios en la legislación más relevantes es el relativo a la reforma laboral. La CEOE apoyó el cambio, reconociendo que sus demandas habían sido recogidas. Los sindicatos convocaron una huelga general por considerar que la reforma laboral vulneraba la Constitución. De hecho, la actitud combativa de los sindicatos ha sido una constante desde el inicio del Gobierno popular. Los sindicatos han rechazado todas aquellas propuestas que versaran sobre la reducción del gasto público o la alteración de las condiciones laborales.

De esta primera parte del análisis se destaca que ha habido un cambio de actitud de los sindicatos y de la patronal que se inicia con la reforma laboral del gobierno socialista ya que sirve como ejemplo de intensificación de un modelo de ajuste fiscal que se reforzará con la alternancia en el ejecutivo. 
Tabla 2. Reformas planteadas por el Gobierno de Rajoy (2012)

\begin{tabular}{|c|c|c|c|c|c|c|c|}
\hline \multicolumn{4}{|c|}{ Características de las reformas } & \multicolumn{4}{|c|}{ Respuestas de los actores sociales } \\
\hline Fecha & Nombre & Objetivo & Principales medidas & CEOE & & UGT & $\mathrm{CCOO}$ \\
\hline $\begin{array}{l}11 / 01 / 2 \\
012\end{array}$ & & $\begin{array}{l}\text { Ajustar el déficit } \\
\text { en } 15.000 \\
\text { millones de } €\end{array}$ & $\begin{array}{l}\text { Reforma IRPF } \\
\text { Congelación salarial } \\
\text { funcionarios } \\
\text { Ajuste presupuestario de } 8.900 \\
\text { millones de } €\end{array}$ & Apoyo & & chazo & Rechazo \\
\hline $\begin{array}{l}03 / 02 / 2 \\
012\end{array}$ & $\begin{array}{l}\text { R.D. de } \\
\text { Saneamiento } \\
\text { del Sistema } \\
\text { Financiero }\end{array}$ & $\begin{array}{l}\text { Saneamiento de } \\
\text { los activos } \\
\text { inmobiliarios de } \\
\text { la banca }\end{array}$ & $\begin{array}{l}\text { Aumento de } 50.000 \text { millones de } \\
€ \text { las provisiones de la banca } \\
\text { Aumento de } 15.000 \text { millones de } \\
€ \text { al FROB }\end{array}$ & Apoyo & $\begin{array}{l}\text { Apo } \\
\text { pero } \\
\text { cons } \\
\text { med } \\
\text { pocc } \\
\text { amb }\end{array}$ & \begin{tabular}{l|l} 
oyo, & \\
ro se & \\
nsidera & \\
edidas & $c$ \\
co & r \\
biciosa &
\end{tabular} & $\begin{array}{l}\text { Apoyo, pero } \\
\text { considera } \\
\text { que no } \\
\text { resuelve }\end{array}$ \\
\hline $\begin{array}{l}11 / 02 / 2 \\
012\end{array}$ & $\begin{array}{l}\text { Reforma } \\
\text { laboral }\end{array}$ & $\begin{array}{l}\text { Flexibilización } \\
\text { del mercado de } \\
\text { trabajo }\end{array}$ & $\begin{array}{l}\text { Flexibilización mercado de } \\
\text { trabajo } \\
\text { Descentralización negociación } \\
\text { colectiva } \\
\text { Ampliación cláusulas de } \\
\text { descuelgue }\end{array}$ & Apoyo & $\begin{array}{l}\text { Recl } \\
\text { Hue } \\
\text { Mar }\end{array}$ & $\begin{array}{l}\text { chazo } \\
\text { elga gen } \\
\text { arzo) }\end{array}$ & neral $(26$ \\
\hline $\begin{array}{l}07 / 03 / 2 \\
012\end{array}$ & & $\begin{array}{l}\text { Reducción del } \\
\text { gasto de las } \\
\text { AAPP }\end{array}$ & $\begin{array}{l}\text { Ajuste de un } 40 \% \text { en inversión } \\
\text { pública }\end{array}$ & $\begin{array}{l}\text { Apoyo, } \\
\text { propuesta de } \\
\text { reducir } \\
\text { número } \\
\text { funcionarios }\end{array}$ & & Rechazo & Rechazo \\
\hline \begin{tabular}{|l|}
$09 / 03 / 2$ \\
012 \\
\end{tabular} & $\begin{array}{l}\text { Línea de } \\
\text { crédito a } \\
\text { AAPP para } \\
\text { pago a } \\
\text { proveedores }\end{array}$ & & $\begin{array}{l}\text { Acceso de las AAPP a } \\
\text { préstamos sindicados }\end{array}$ & Apoyo & - & & $\begin{array}{l}\text { Rechazo, por } \\
\text { considerar } \\
\text { que la banca } \\
\text { es la máxima } \\
\text { beneficiada } \\
\end{array}$ \\
\hline $\begin{array}{l}23 / 03 / 2 \\
012\end{array}$ & $\begin{array}{l}\text { Ley de } \\
\text { Transparencia }\end{array}$ & $\begin{array}{l}\text { Administraciones } \\
\text { Públicas más } \\
\text { transparentes }\end{array}$ & $\begin{array}{l}\text { Obligatoriedad de las AAPP de } \\
\text { informar sobre el gasto público } \\
\text { Consulta ciudadana sobre } \\
\text { actividad de las AAPP }\end{array}$ & Apoyo & - & & - \\
\hline $\begin{array}{l}30 / 04 / 2 \\
012\end{array}$ & \begin{tabular}{|l|} 
Ley de \\
Estabilidad \\
Presupuestaria
\end{tabular} & $\begin{array}{l}\text { Estabilidad } \\
\text { presupuestaria } \\
\text { en } 2020\end{array}$ & $\begin{array}{l}\text { Establecimiento de un límite } \\
(0,4 \%) \text { en el déficit de las } \\
\text { AAPP }\end{array}$ & Apoyo & Recl & chazo & Rechazo \\
\hline $\begin{array}{l}11 / 05 / 2 \\
012\end{array}$ & $\begin{array}{l}\text { Reforma del } \\
\text { Sistema } \\
\text { Financiero }\left(2^{\mathrm{a}}\right. \\
\text { Fase })\end{array}$ & $\begin{array}{l}\text { Reforma del } \\
\text { sistema } \\
\text { financiero }\end{array}$ & $\begin{array}{l}\text { Incremento en las provisiones } \\
\text { de } 28.000 \text { millones de } €\end{array}$ & Ароуо & $\begin{array}{l}\text { Apo } \\
\text { pero } \\
\text { sugi } \\
\text { naci } \\
\text { zaci }\end{array}$ & \begin{tabular}{l|l} 
oyo, & $f$ \\
oo & $\mathrm{s}$ \\
siere & $\mathrm{n}$ \\
cionali & $\mathrm{c}$ \\
iones. & $\mathrm{i}$
\end{tabular} & $\begin{array}{l}\text { Apoyo, pero } \\
\text { sugiere } \\
\text { mayor } \\
\text { coordinación } \\
\text { internacional }\end{array}$ \\
\hline $\begin{array}{l}13 / 07 / 2 \\
012\end{array}$ & & $\begin{array}{l}\text { Ajuste fiscal de } \\
65.000 \text { millones } \\
\text { de } € \text { en dos años }\end{array}$ & $\begin{array}{l}\text { Subida del IVA } \\
\text { Reducción salarios funcionarios } \\
\text { Reducción presupuestaria } \\
\text { Reforma prestación por } \\
\text { desempleo } \\
\text { Reforma gobierno local } \\
\text { Reducción subvenciones públicas } \\
\text { Flexibilización horarios } \\
\text { comerciales }\end{array}$ & $\begin{array}{l}\text { Apoyo, sugic } \\
\text { mayor ajuste } \\
\text { el gasto públ } \\
\text { Críticas a la } \\
\text { subida del IV }\end{array}$ & $\begin{array}{l}\text { ere } \\
\text { e en } \\
\text { lico. } \\
\text { VA. }\end{array}$ & Rechaz & Rechazo \\
\hline
\end{tabular}

Fuente: Elaboración propia.

Hasta ese momento los sindicatos daban apoyo a un programa keynesiano cuya duración fue relativamente corta. Además, en el plano ideológico la CEOE ha legitimado todas las reformas del gobierno de Mariano Rajoy pero no lo hizo con el gobierno 
socialista. En este caso se observa una fuerte correlación ideológica entre la CEOE y el Partido Popular. Tal es así que en 2009 el expresidente de la patronal Gerardo Díaz Ferrán declaró en una entrevista que el "PP es más receptivo a nuestras propuestas" (El País, 01/11/2009). De lo contrario, los sindicatos se han mostrado críticos con las reformas del gobierno socialista cuando éstas proponían recortes sociales. Por las mismas razones los sindicatos han rechazado todas las reformas del Gobierno popular.

\section{EL POSICIONAMIENTO PÚBLICO DE LOS ACTORES SOCIALES FRENTE A LOS TEMAS DE LA AGENDA PÚBLICA}

La patronal y los sindicatos responden a las acciones del Gobierno de acuerdo con sus propios intereses. Si bien es cierto que en algunas ocasiones alguno de ellos puede ceder en su reivindicación en un momento de complicidad, la decisión de apoyar o rechazar una iniciativa gubernamental está en gran medida justificada por una razón estratégicoideológica interna. A continuación se dará cuenta de la posición programática de cada uno de los actores sociales en relación con siete políticas públicas concretas, a saber, sanidad, educación, fomento, industria, relaciones laborales, administración pública y seguridad social. La complejidad de las políticas públicas impide plantear un análisis unidimensional en el que solamente quepa un aspecto referente al gasto público. Se propone examinar la opinión de los actores sociales sobre políticas públicas en cinco ejes: a) necesidad de reducir el gasto público; b) insostenibilidad del modelo de la política pública; c) urgencia en la implementación de la reforma; d) efecto negativo de la reforma en la cohesión social; y e) efecto negativo de la reforma en el crecimiento económico. Esta propuesta de análisis permite observar con más detalle las áreas de conflicto existente entre los actores sociales. El rango de los valores se ha propuesto de 0 a 1 , siendo 0 la situación de menos concordancia con el enunciado. Los valores pueden variar entre ejes. Los valores se presentan en gráficos radiales por cada una de las siete políticas analizadas en los que el centro equivale a valores de 0 y el borde a 1 . Este tipo de ejes permiten una sugerente visualización multidimensional. Las posiciones iniciales de los actores sociales quedaban reflejadas en los siguientes textos: por parte de la CEOE, "Principios y propuestas para recuperar la competitividad, el crecimiento y el empleo en España", fechado el 2 de Diciembre de 2009. La CEOE asumía cuatro retos, a saber, la sostenibilidad de las cuentas públicas, la ineficiencia del mercado de trabajo, la falta de competitividad de la economía y el difícil acceso a la financiación. Por parte de la UGT, el texto de referencia sería la "Resolución del Primer Comité Interconfederal", de 25-26 de Noviembre de 2009. La UGT defendía una mejora salarial, el fortalecimiento de la negociación colectiva, la defensa del empleo, la formación de los trabajadores y la igualdad de trato y de oportunidades. Finalmente, el Consejo Confederal de CCOO aprobó un informe el 5 de Mayo de 2009 (Cuadernos de Información Sindical -1) en el que se apostaba por transformar el modelo productivo, asegurar el empleo y fortalecer la negociación colectiva. Siguiendo estos documentos, era previsible la confrontación en todos los aspectos de la política laboral, aunque el margen de compromiso sobre el resto de políticas era relativamente alto. ¿Qué aspectos de las políticas públicas han sido de mayor rivalidad programática entre la CEOE, UGT y CCOO a lo largo de la crisis económica? A continuación se muestran los posicionamientos de los actores sociales. La CEOE 
corresponde a la línea negra mientras que los sindicatos, por afinidad programática, quedan solapados bajo la línea gris.

Figura 1. Posiciones ideológicas de los actores sociales durante la crisis

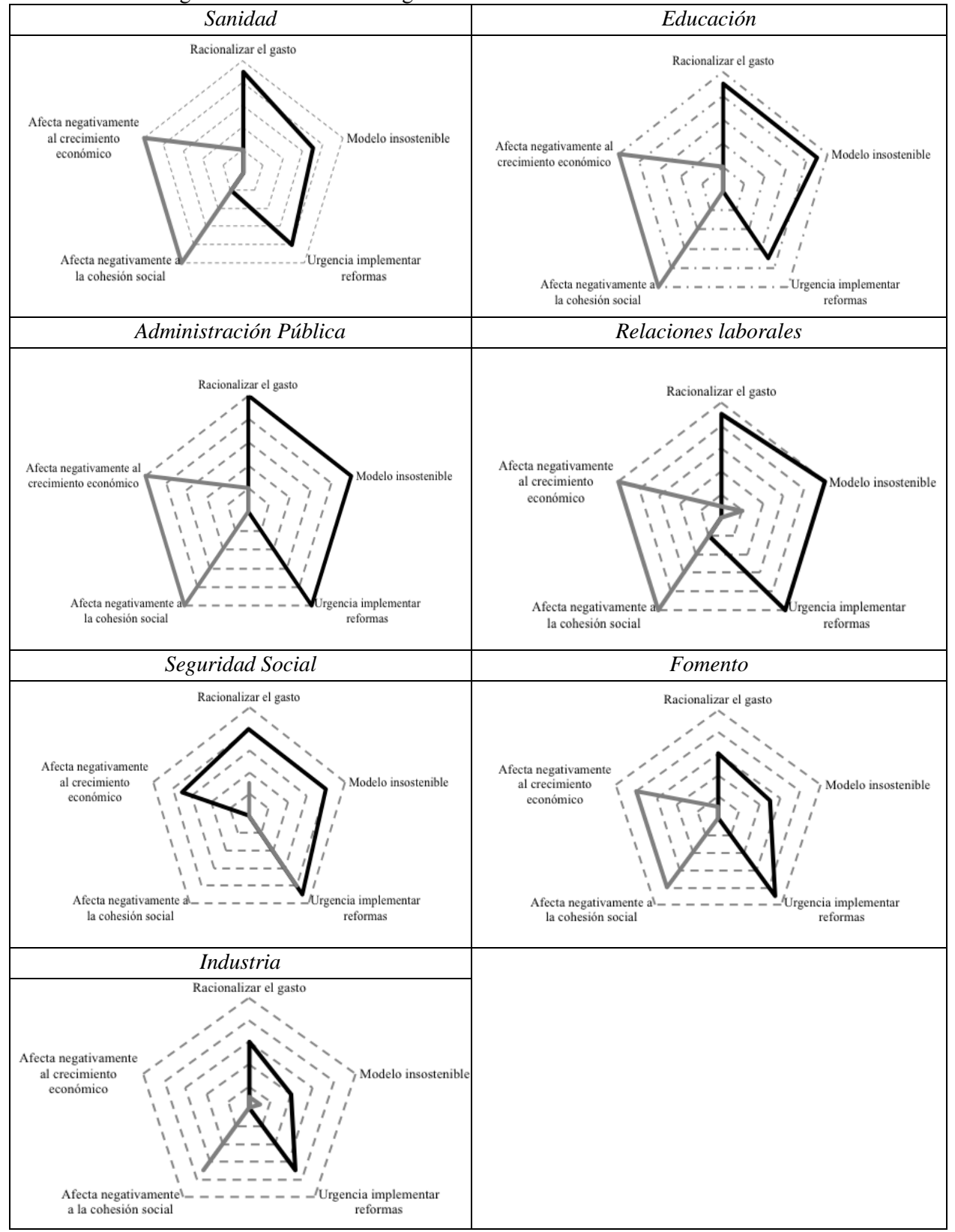

Fuente: Elaboración propia.

Nota: La línea negra corresponde a la CEOE. La línea gris, a los Sindicatos. 
La principal tendencia que se deduce de los gráficos es la falta de afinidad programática en todas las políticas públicas seleccionadas. Existen situaciones, como en la política de fomento y la política de industria, en la que las diferencias no son tan exageradas. No obstante, escasos puntos de encuentro se observan en el conjunto de políticas. Esta situación señala que los actores sociales han adoptado planteamientos opuestos durante la crisis económica impidiendo las bases para un diálogo social tripartido continuado. Para empezar, los sindicatos se han opuesto intensamente a los recortes en sanidad. Ante el anuncio de reformas del Gobierno popular, la UGT comentó que cualquier medida de copago sanitario generaría sufrimiento a la población (nota de prensa, 12/07/2012). CCOO denunció que la falta de recursos estaba perjudicando la calidad del servicio. De lo contrario, la CEOE aseguró que sería posible gestionar el presupuesto en sanidad para reducirlo de acuerdo a los objetivos de déficit de España. En este sentido, un informe de la Comisión de Concesiones y Servicios de la CEOE sugirió que la financiación privada para recuperar la inversión en el sector (ver El sector de las infraestructuras públicas, 16/03/2012). Similares planteamientos caracterizan la política educativa. La UGT se oponía notablemente a los recortes en educación (nota de prensa, 18/05/2012). Para CCOO los recortes en educación son inasumibles y todas las protestas de estudiantes y maestros, justificadas (nota de prensa, 23/05/2012). El planteamiento de la CEOE es prácticamente opuesto al de los sindicatos. La patronal reclamó una reforma integral de la educación el todos sus ámbitos, desde una mayor conexión entre la FP y la empresa hasta la potenciación de las ciencias y la ingeniería en las universidades (ver Documento del Círculo de Empresarios y la CEOE sobre competitividad de la industria española, 10/05/2011). Tras manifestar que el rendimiento escolar debe mucho a la herencia genética, la CEOE es partidaria del cheque escolar, la reducción de la plantilla femenina entre el profesorado, la reducción del gasto y la competición entre centros públicos y concertados (El País, 22/06/2011). El tamaño de las administraciones públicas es un tema de máxima importancia para la CEOE. En un comunicado valorando las prioridades de los presupuestos generales de 2013 publicado el 18 de Julio de 2012, la CEOE enfatiza la urgencia de reducir la estructura y gastos estructurales del conjunto de las Administraciones públicas. Los sindicatos mantienen opiniones contrarias. Para la UGT los recortes en la Administración Pública son vistos como una agresión a la Constitución y la democracia. CCOO ve ilegales los ajustes salariales en las Administraciones Públicas y considera que las reformas no tienen más que efectos negativos en la calidad de vida del funcionariado. Como en otras ocasiones, los sindicatos impulsaron movilizaciones de protesta para el 19 de Julio de 2012.

A pesar de que la última reforma de las pensiones se canalizó por diálogo social a mediados de 2011, la CEOE insiste en la necesidad de revisar el acuerdo si las condiciones macroeconómicas no son las oportunas. De tal forma, la patronal aceptaría revisar la edad de jubilación, reducir las pensiones, reducir las contribuciones empresariales a la seguridad social y cambiar el cálculo para acceder a una pensión. La opinión de los sindicatos está más condicionada por su participación en el diálogo social. Ambos sindicatos se muestran satisfechos por el último acuerdo sobre pensiones. Las discusiones referidas al mercado laboral son las que albergan mayor polaridad. Los sindicatos parten de la idea de que el desempleo es generado por problemas de competitividad de la economía española. Ante la elevada tasa de desempleo, la UGT defiende que sin crecimiento económico no se logra crear empleo (nota de prensa, 04/06/2012). CCOO destaca que las reformas laborales son contrarias a la Carta Social Europea y los convenios de la Organización Internacional del Trabajo (OIT) (EuropaPress, 27/02/2012). La CEOE culpa a la rigidez del mercado laboral y 
a la perversión de las prestaciones por desempleo. De hecho, la patronal aplaude que la última reforma laboral pretende combatir asuntos olvidados como el absentismo o la burocratización de los procesos. Para la patronal, en definitiva, la reforma laboral es una cuestión urgente a pesar de que sus efectos tarden en materializarse (El Economista, 27/02/2012). Para evitar tensiones, la CEOE reclama también que se revise el derecho a huelga.

En la política de fomento se evidencia menos polaridad. Es además un área particular en la que incluso la $\mathrm{CEOE}$ altera su discurso de austeridad proponiendo una inversión pública de 80.600 millones de euros (ABC, 06/03/2012). La actitud de la patronal pone de manifiesto la relevancia de las infraestructuras para el crecimiento económico que es también aprovechado para potenciar un acuerdo de inversión público-privada con el Ministerio de Fomento. Si bien los sindicatos no desean las privatizaciones en las infraestructuras, si son partidarios de mantener el gasto en la prevención de incendios, el mantenimiento de las carreteras, la minería, el transporte público y en otras partidas. Como en otros sectores, los sindicatos se han movilizado contra los anuncios de liberalización de las infraestructuras como en los referidos a Renfe durante el 3 de Agosto de 2012. El objetivo principal de los sindicatos en relación con la política industrial en los últimos años ha sido triple: evitar los despidos de trabajadores, evitar un incremento de impuestos y velar por un cambio e modelo productivo. Ambos sindicatos se muestran contrarios a los recortes en políticas de industria, turismo y energía, que supone en algunos casos una variación anual negativa del 90\%. La patronal defiende que es preciso apoyar al emprendedor de forma inminente por lo que propone crear vías de acceso a la financiación y a las fuentes energéticas para que la economía española se adapte a la estrategia Europa 2020 (ver Plan de competitividad industrial 2010 de la CEOE). Si bien la patronal pone el acento en el empresariado y sus necesidades, los sindicatos fijan su interés en el empleo. En general, el repaso a las demandas de los actores sociales demuestra que el consenso es una meta de difícil recorrido. Existen diferentes criterios en todas las políticas analizadas. En algunos casos los criterios se ven reforzados por la complicidad del Gobierno, aspecto que aleja la necesidad de diálogo social y fuerza a estrategias de influencia basadas en las movilizaciones.

\section{LA CAPACIDAD DE LOS ACTORES SOCIALES PARA LOGRAR ACUERDOS}

El objetivo de esta sección es examinar el aspecto negociador de los actores sociales. Existe un interés teórico por expandir el análisis más allá de la lógica de afiliación que se refiere a los aspectos organizativos y programáticos de las asociaciones de intereses. En los países corporatistas como España las demandas circunscritas al primer grupo suelen potenciarse mediante la concertación social o pactos sociales. Consideramos que analizar este aspecto tiene un corto recorrido ya que muy pocos pactos sociales han visto la luz en España en los últimos años. Por este motivo se centra el análisis en lo acontecido en la negociación colectiva. Siguiendo a Windmuller (1989:15, citado en Köhler y Martín Artiles, 2010:576), la negociación colectiva se entiende como "el proceso de toma de decisiones entre partes que representan los intereses de los empleadores y empleados. El objeto primordial es la negociación y aplicación continua de un conjunto de reglas pactadas que regulan las condiciones reales y de procedimiento de las relaciones de trabajo y determinan la relación entre las partes en este proceso". 
Hasta la entrada en vigor de la última reforma laboral en 2012 que introduce una mayor descentralización en las negociaciones entre empleadores y trabajadores, el nivel preferente de negociación en España ha sido la provincia. En otras palabras, las normas que regulaban las condiciones de trabajo se negociaban a nivel provincial por los representantes de los empresarios y de los trabajadores. En algunos sectores se priorizan los convenios colectivos estatales o autonómicos, pero no son mayoritarios. Ello ha tenido algunas repercusiones en la lógica negociadora de los actores sociales. Las cúpulas nacionales no participan directamente en la negociación. La CEOE, la UGT y CCOO participan en el proceso consensuando unas líneas maestras que fijan las exigencias sobre salarios y condiciones laborales. Serán sus organizaciones territoriales las encargadas de alcanzar acuerdos dentro de estos límites. Dado que a nivel estatal no existe negociación, las cúpulas estatales se comportan de forma estratégica influenciadas por el clima político. La siguiente tabla muestra la influencia de dicho clima en los acuerdos para la negociación colectiva. Con anterioridad a 2008, exceptuando el año 2001, se habían alcanzado cinco acuerdos y dos prórrogas. Desde el inicio de la crisis los actores sociales solamente han sido capaces de llegar a un acuerdo formal, prorrogar los objetivos de $2007 \mathrm{y}$ comprometerse informalmente en dos ocasiones a acometer la renovación de convenios colectivos urgentes. Este cambio de tendencia demuestra que la crisis económica ha condicionado la voluntad negociadora de los actores sociales.

Tabla 3. Acuerdos en materia de negociación colectiva

\begin{tabular}{|c|l|}
\hline Año & \multicolumn{1}{|c|}{ Acuerdo } \\
\hline 2001 & - \\
\hline 2002 & Acuerdo para la negociación colectiva (BOE, 17 enero 2002) \\
\hline 2003 & Acuerdo para la negociación colectiva (BOE, 24 febrero 2003) \\
\hline 2004 & $\begin{array}{l}\text { Prórroga para el año 2004 del Acuerdo para la Negociación Colectiva del 2003 } \\
\text { (BOE, 31 de diciembre 2003) }\end{array}$ \\
\hline 2005 & Acuerdo para la negociación colectiva (BOE, 7 marzo 2005) \\
\hline 2006 & $\begin{array}{l}\text { Prórroga para el año 2006 del Acuerdo para la Negociación Colectiva del 2005 } \\
\text { (BOE, 10 febrero 2006) }\end{array}$ \\
\hline 2007 & Acuerdo para la negociación colectiva (BOE, 24 febrero 2007) \\
\hline 2008 & $\begin{array}{l}\text { Prórroga para el año 2008 del Acuerdo para la Negociación Colectiva del 2007 } \\
\text { (BOE, 14 enero 2008) }\end{array}$ \\
\hline 2009 & $\begin{array}{l}\text { Compromiso de actuación entre CEOE y CEPYME y CCOO y UGT sobre la } \\
\text { negociación colectiva pendiente de 2009 }\end{array}$ \\
\hline 2010 & Acuerdo para la negociación colectiva 2010, 2011 y 2012 (BOE, 22 febrero 2010) \\
\hline 2011 & $\begin{array}{l}\text { Compromiso de actuación entre CEOE, CEPYME, CCOO y UGT sobre la } \\
\text { negociación colectiva pendiente }\end{array}$ \\
\hline
\end{tabular}

Fuente: Elaboración propia a partir de información del Ministerio de Trabajo.

¿Cuál ha sido la repercusión de esta tendencia en la renovación de convenios colectivos? La Figura 2 demuestra que la crisis económica ha afectado negativamente en la negociación colectiva. Si bien la media de convenios colectivos firmados hasta 2008 superaba con creces la cifra de 5.000, el año 2011 solamente posibilitó la firma de 3.068 convenios colectivos. Nótese que el descenso de convenios colectivos en los últimos tres años de la serie es rotundo. Cabe destacar que los convenios colectivos no han sido un 
instrumento eficaz para la reducción de la tasa de desempleo. Este hecho se puede empezar a observar en el año 2008 y es evidente en años sucesivos.

Figura 2. Tasa de desempleo y convenios colectivos

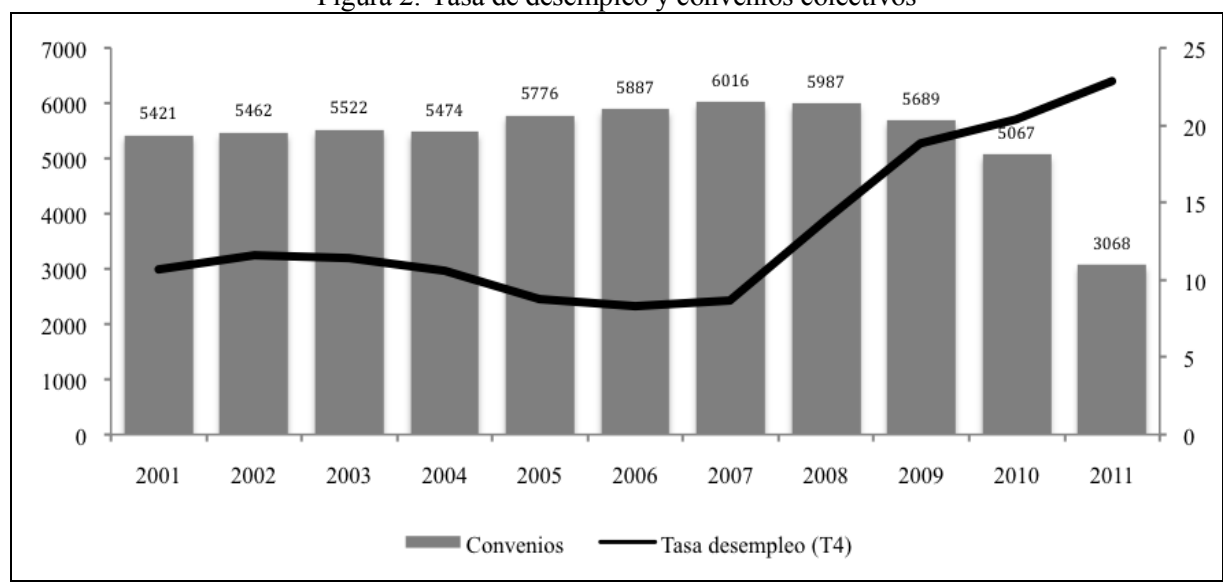

Fuente: Instituto Nacional de Estadística (INE)

Nota: El eje izquierdo cifra el número de convenios colectivos. El eje derecho representa los porcentajes de la tasa de desempleo correspondiente al cuarto trimestre de cada año.

No se puede disociar la capacidad de negociación de los actores sociales con la máxima expresión de conflicto entre ellos: la huelga. Existen varias explicaciones a las huelgas que requieren atención. Una de ellas las justifica ideológicamente, especialmente en los países de tardía industrialización entre los que se incluye España.

Figura 3. Huelgas y seguimiento de trabajadores

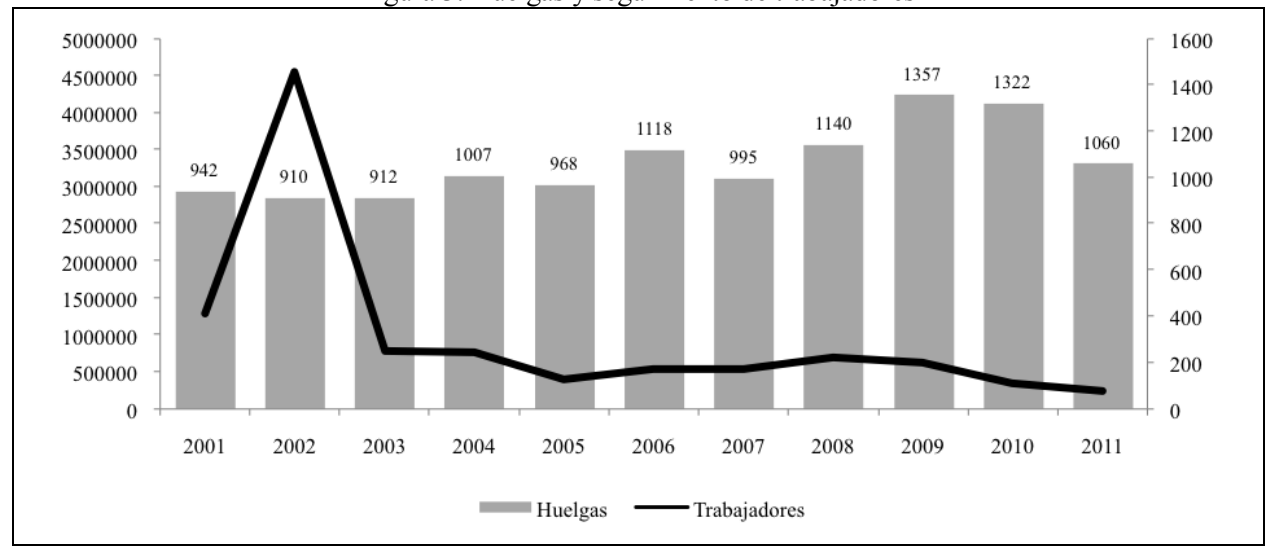

Fuente: Instituto Nacional de Estadística (INE)

Nota: El eje izquierdo corresponde al número de trabajares que secundaron convocatorias de huelga. El eje derecho indica el número de huelgas.

Otra se refiere a las razones económicas y a la huelga como respuesta a un ciclo largo de contención salarial (Grint, 2003). Uno de los condicionantes de las huelgas es el ciclo económico. Cuando éste es expansivo, los trabajadores están más interesados en la 
conflictividad para reclamar mejoras laborales. Si es un ciclo depresivo, el cierre de empresas y el desempleo influyen en una menor conflictividad. La Figura 3 combina datos sobre el número de huelgas y su seguimiento entre los años 2001 y 2011. Si bien es cierta la influencia del ciclo depresivo, especialmente reflejada en los datos de 2011, los años anteriores a este fueron especialmente agitados en convocatorias de huelgas aunque no en seguimiento de trabajadores. Lo que pone de manifiesto la Figura 3 es que los trabajadores han rebajado su movilización huelguista a causa de la crisis en paralelo a la incapacidad de los sindicatos de renovar convenios colectivos. También es cierto que la destrucción de empleo se ha ido acrecentando exponencialmente a lo largo de los años por lo que la presión de los ocupados para no ir a la huelga ha sido mayor. En cualquier caso, estos datos ponen de manifiesto que los sindicatos han visto mermado uno de sus principales recursos de presión.

\section{LA VALORACIÓN CIUDADANA DEL PAPEL DE LOS ACTORES SOCIALES EN LA ACTUAL CRISIS}

La actividad de los actores sociales no es ajena a la opinión pública. Teniendo en cuenta el ya citado compromiso constitucional de empresarios y sindicatos, el control ciudadano de los actores sociales se vuelve incluso de obligada ejecución. Estudios en profundidad son, no obstante, escasos. Es posible encontrar preguntas sobre el prestigio de los actores sociales en los estudios del Centro de Investigaciones Sociológicas (CIS) que los acostumbran a situar en posiciones intermedias. Otros barómetros, como los de la Fundación Ortega-Marañón (www.ortegaygasset.edu), se fijan en el clima empresarial. Sin embargo, se trata de un área de investigación poco desarrollada, de poca repercusión mediática. Los resultados que se presentan en este artículo provienen de una encuesta sobre cultura y opinión pública en España con una muestra de 1.761 personas realizada mediante técnica CATI con el equipo humano de Metroscopia entre el 20 de junio y el 11 de julio de 2011 (nivel de confianza establecido al $95,5 \%$ con un margen de error de $\pm 2,8 \%$ ). En las siguientes páginas se examinan las opiniones ciudadanas sobre temas transversales que se han discutido en secciones anteriores, a saber, la responsabilidad de los actores sociales en la crisis económica, la priorización del interés general a los intereses particulares de los actores sociales y, por último, la representación competente de los empresarios y trabajadores por parte de la CEOE, la UGT y CCOO. Es preciso destacar que la opinión ciudadana no sirve como evaluación sagrada de la actividad de los actores sociales. En todo caso serán sus miembros los que cumplan dicha misión. La opinión ciudadana se emplea en este estudio como pulsímetro de una tendencia manifiesta en la sociedad española de cinismo democrático que animaría a los actores sociales a explicarse mejor y ser más transparentes.

De las muchas posibilidades que ofrece la encuesta utilizada, se ha optado por la sencillez en la presentación de los resultados de acuerdo con las exigencias del artículo. Para cada uno de los tres asuntos abordados se presentan los porcentajes de respuesta del conjunto de participantes en la encuesta. Los porcentajes siguen una lógica ordinal permitiendo posiciones de "nada", "poco", "bastante" y "mucho". Se efectúa una comparación que pone de manifiesto las diferentes percepciones ciudadanas sobre los actores sociales por cada uno de los temas. La Figura 4 corresponde a la responsabilidad de los actores sociales en la crisis económica. Responsabilidad se entiende como "contribución" a la crisis económica y no como "obligación a repararla". 
Figura 4. La responsabilidad de los actores sociales en la crisis según la opinión pública

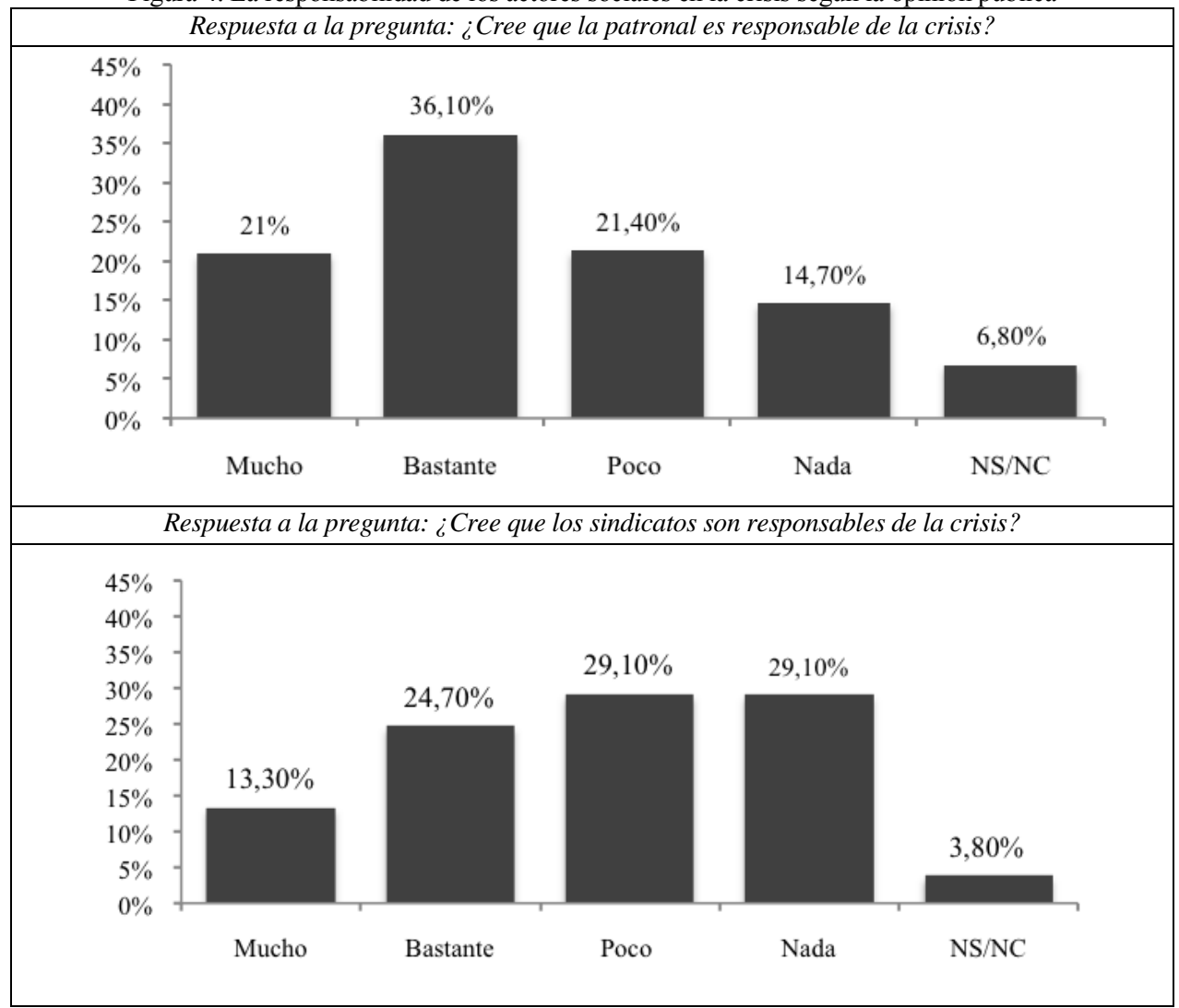

Fuente: Elaboración propia a partir de la encuesta "Cultura y representación política en España”.

La Figura 5 recoge las opiniones relacionadas con la defensa del interés general por parte de los actores sociales. Entendiendo que el interés general se contrapone al interés particular, el gráfico muestra cómo los ciudadanos valoran la capacidad de los actores sociales de sacrificar el beneficio particular (demandas individuales) por el beneficio colectivo. Finalmente, en la Figura 6 se examina un tema central en la representación de intereses: ¿representan sindicatos y patronal a trabajadores y empresarios? Asumiendo que en España se ha institucionalizado el criterio de monopolio en la representación de intereses, es oportuno valorar si la ciudadanía reconoce que esa función está ejemplarmente desarrollada o, de lo contrario, si patronal y sindicatos son vistos como meras organizaciones elitistas alejadas de su principal cometido.

En relación con el primer tema, los resultados de la encuesta otorgan diferentes niveles de responsabilidad entre los actores sociales. Primero, la CEOE obtiene mayores porcentajes de responsabilidad que los sindicatos. El $36 \%$ de los encuestados creen que la patronal es bastante responsable de la crisis económica y el $21 \%$ considera que lo es mucho. En comparación, casi el $25 \%$ piensa que los sindicatos son bastante responsables de la crisis y apenas el 13,3\% los responsabilizan mucho. Casi el $60 \%$ de los encuestados otorgan poca "culpabilidad" a los sindicatos, porcentaje que se reduce a algo más del 35\% para la CEOE. 
Evitamos aventurar conclusiones sesgadas a partir de estos resultados como la tentación de responsabilizar más a empresarios que a trabajadores de la crisis por la propia naturaleza económica de los primeros. Lo máximo que se puede extraer de esta comparación es que existe una mayor tolerancia al discurso sindical de los orígenes de la crisis económica y que, posiblemente, la CEOE no ha hecho lo suficiente para alejarse de la culpabilidad que le reivindica la opinión pública.

Figura 5. Los actores sociales y el interés general en la crisis según la opinión pública

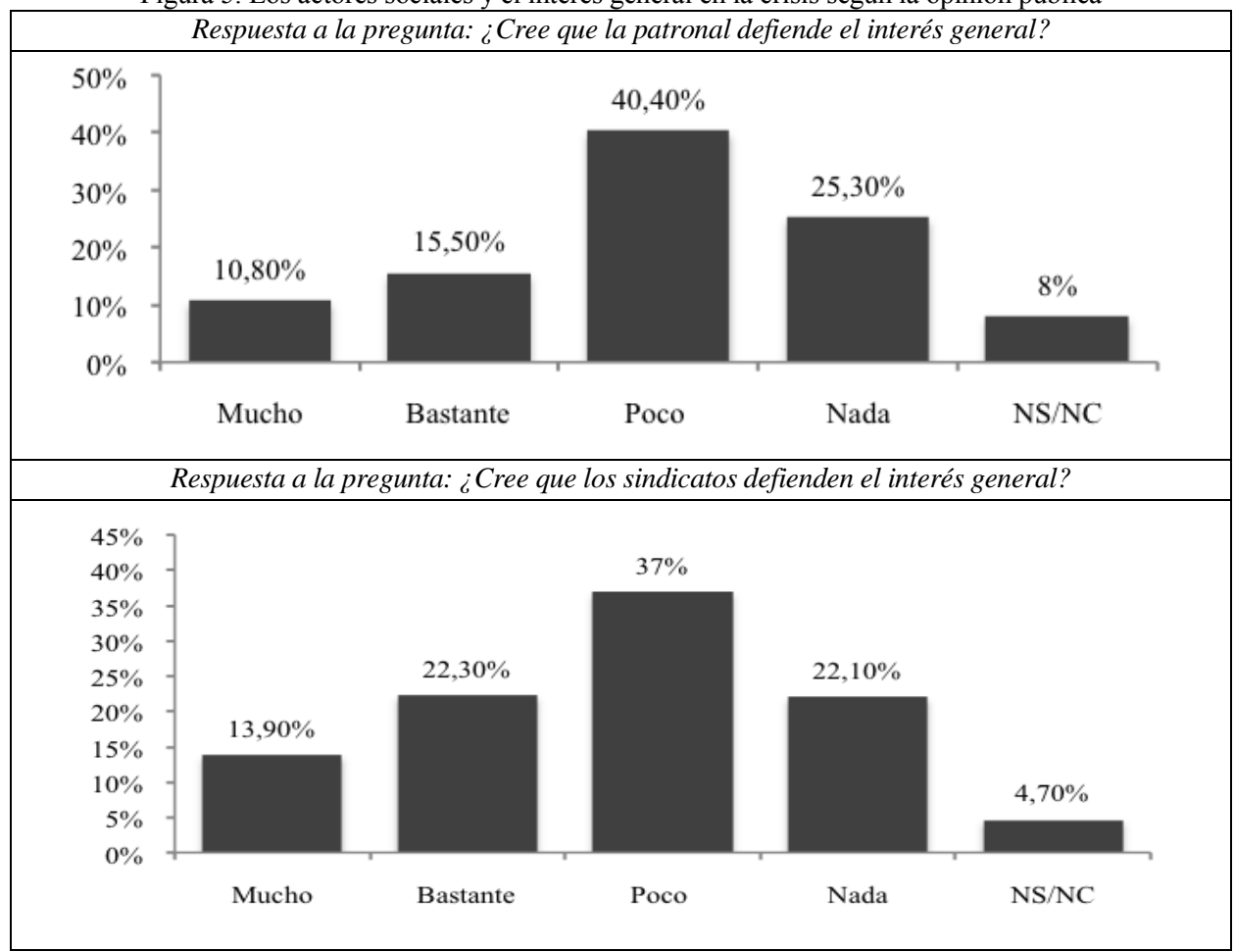

Fuente: Elaboración propia a partir de la encuesta "Cultura y representación política en España"

La moderación aplicada a los resultados de los anteriores gráficos se explica por las variaciones observadas en los siguientes gráficos. Cuando la opinión pública valora el grado de templanza de las demandas de sindicatos y patronal no se observan distribuciones muy desiguales. El 40,4\% de los encuestados opina que la patronal está poco dispuesta a defender el interés general. Este porcentaje es muy similar al 37\% para los sindicatos. Nótese que estos resultados son congruentes con el comportamiento de los actores sociales durante la crisis. En las secciones anteriores se ha apuntado la polaridad ideológica entre sindicatos y patronal y sus dificultades para consensuar políticas estables. Estos bloqueos parecen haber llegado a la opinión pública que pone en cuestión la capacidad de ambos para dejar atrás disputas interesadas.

Si bien la opinión pública considera que los actores sociales priman los intereses particulares al interés general, el siguiente paso es analizar qué tan bien la opinión pública cree que la patronal y los sindicatos representan a empresarios y trabajadores. Cabría esperar 
que la negativa a ceder en el interés general se tradujera en una poderosa representación individual. No parece que sea así. Los mayores porcentajes se sitúan en la posición poco. Es curioso que los valores sean casi idénticos en ambos gráficos a excepción de los relativos a Nada -la patronal y sindicatos no representan nada los intereses de empresarios y trabajadores- que se explica por la variación de respuestas NS/NC que, a su vez, podría indicar un mayor desconocimiento de la patronal. Viendo el gráfico relativo a los sindicatos se aprecia que los porcentajes para Mucho y Nada son prácticamente iguales, aspecto que sugiere que éstos disfrutan de similares niveles de defensores vigorosos como de detractores acérrimos.

Figura 6. La representación de intereses de los actores sociales según la opinión pública

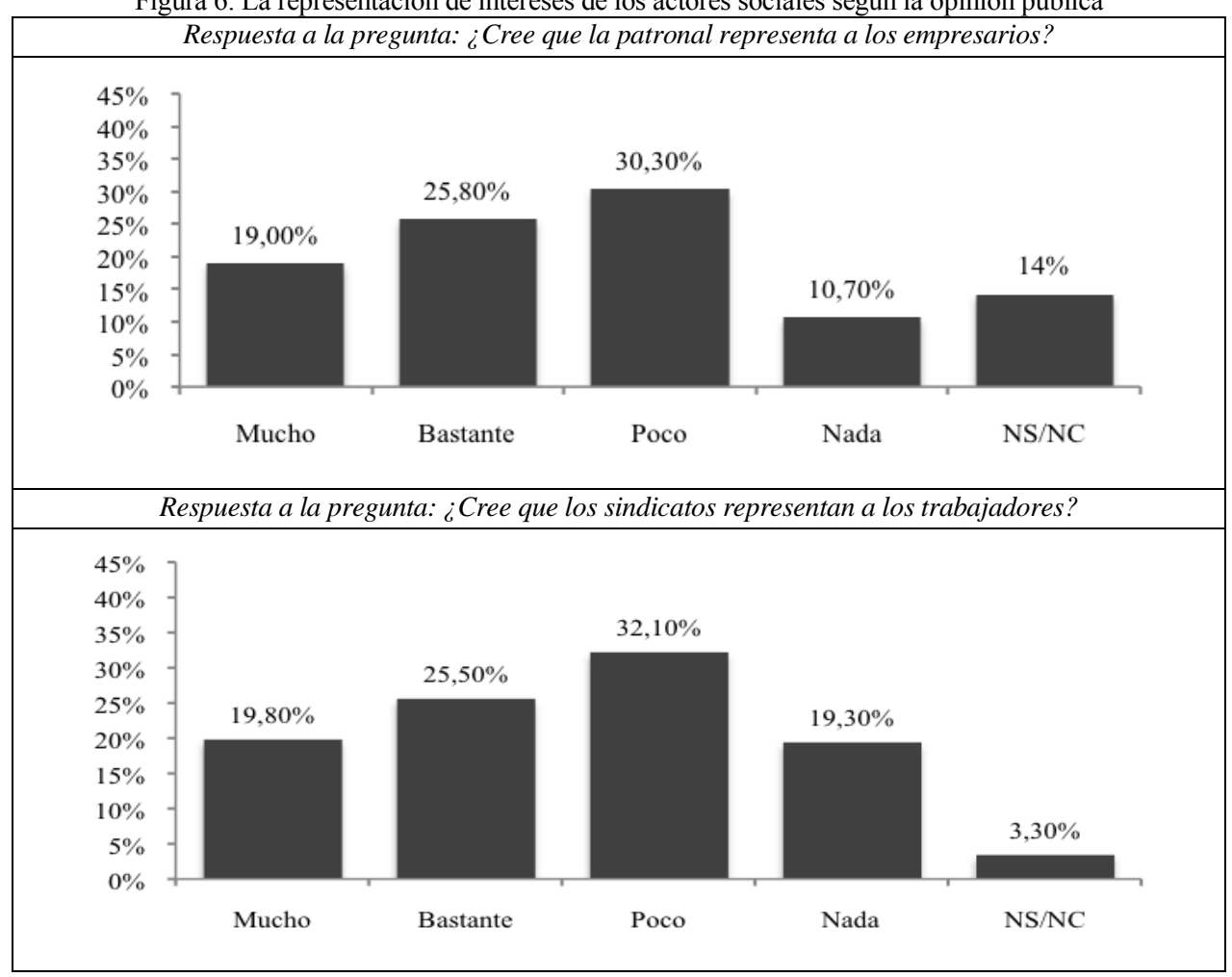

Fuente: Elaboración propia a partir de la encuesta "Cultura y representación política en España"

Acabamos de ver que la opinión pública tiene unas impresiones altamente mejorables sobre los actores sociales. La opinión ciudadana puede entenderse como un incentivo moral para provocar cambios en su funcionamiento interno ya que muchos ciudadanos piensan que no ejercen sus funciones de representación de forma espléndida. Estas consideraciones no son insignificantes a la luz del gran número de beneficios institucionales de los que gozan los actores sociales más representativos que son sustentados por impuestos. Recién aprobada la Ley de Transparencia, patronal y sindicatos disponen de ejemplos legales a su disposición para adaptar sus estructuras. Si bien es cierto que algunas voces dentro de la CEOE han sugerido que patronal y sindicatos no reciban subvenciones públicas -este es el caso del vicepresidente primero Arturo Fernández-, lo cierto es que la mayoría de miembros de la 
patronal rechazan una financiación sustentada exclusivamente por cuotas (El Mundo, 22/03/2012). Hasta el momento, los cambios patronales corren a cuenta del nuevo presidente de la CEOE Joan Rosell que insiste en reducir personal y salarios. Entre los sindicatos también se discuten cambios. El más importante es una eventual fusión que es impulsada por líderes territoriales -especialmente por las ramas catalanas- pero descartada por las cúpulas estatales que proponen "unidad de acción".

\section{CONCLUSIÓN}

Tres grandes conclusiones se extraen de este trabajo. La primera sugiere una situación de gran rivalidad ideológica entre la patronal y los sindicatos en España durante toda la crisis económica. Se ha observado que en pocas veces los actores sociales han reducido sus pretensiones en beneficio del consenso, incluso adoptando una estrategia de apoyo y/o confrontación gubernamental para alcanzar sus objetivos. Segundo, la carencia de liderazgo de los actores sociales es también visible en las dificultades para la renovación de los convenios colectivos. Si bien a nivel estatal la renovación de los compromisos para la negociación colectiva se ha renovado anualmente -no sin volver mencionar la diferencia cualitativa entre un nuevo acuerdo y la renovación de uno pasado- menor suerte ha caracterizado la negociación de convenios colectivos a nivel provincial. Y tercero, todo ello ha tenido consecuencias en la visión social de los actores sociales. No cabe duda del distanciamiento entre la opinión pública y los representantes de trabajadores y empresarios. Quizás el tema de mayor preocupación se refiere a la poca convicción social sobre la representación efectiva de sindicatos y patronal teniendo en cuenta las garantías institucionales de las que gozan los sindicatos y patronal mayoritarios. No debe pasar desapercibida esta valoración pues el desencanto ciudadano por los actores sociales puede llegar a tener consecuencias perversas en la intermediación de intereses y en la forma de actuar de los actores sociales.

En definitiva, la actual crisis marca un punto de inflexión en la trayectoria de consenso político-económico de crisis pasadas. La incorporación al mercado europeo posibilitó acuerdos sociales que esta crisis no ha sido capaz de estimular. Posiblemente la razón sea, desde un planteamiento de recursos e intercambios, que esta crisis económica está basada en reformas inminentes y un horizonte impreciso en el que escaso margen de demandas existe. De cualquier forma, el debate futuro debe plantear la conformidad del presente status quo constitucional debido a la evidente desconexión entre compromisos y comportamiento. Pero si somos justos en nuestra crítica, posiblemente ningún actor de nuestra democracia podría eludir culpa y responsabilidad.

\section{BIBLIOGRAFÍA}

ACOCELlA, N. y DI BARTOLOMEO, G. (2011), "The cost of social pacts", en Bulletin of Economic Research, $\mathrm{n}^{\mathrm{o}}$ 00, pp.1-18.

AVDAGIC, S., RHODES, M. y VISSER. J. (eds.) (2011), Social pacts in Europe: Emergence, evolution and institutionalization, Oxford, Oxford University Press.

ARASANZ, J. y LÓPEZ MARTÍ, A. (2005), "La concertación social en España (1976-2004): análisis de la construcción socio-histórica de los actores sociales" en Revista universitaria de ciencias del trabajo, $\mathrm{n}^{\mathrm{o}}$ 6, pp.183-200. 
BRANDL, B. y TRAXLER, F. (2011), "Labour relations, economic governance and the crisis: turning the tide again?", en Labor History, vol.52, $\mathrm{n}^{\circ}$ 1, pp. 1-22.

COLINO, C. y COTARELO, R. (eds.) (2012), España en crisis: balance de la segunda legislatura de Zapatero, Madrid, Tirant.

FRIOT, B. (2004), "Resource regime reform and worker status", en B. Clasquin; N. Moncel; M. Harvey y B. Friot (eds), Wage and welfare. New perspectives on Employment and social rights in Europe, Bruselas, PIE.

GRINT, K. (2003), The sociology of work, Cambridge, Polity Press, Blackwell.

HAMANN, K. y KELLY, J. (2011), Parties, elections and policy reforms in Western Europe: Voting for social pacts, Abingdon, Routledge.

HANCKÉ, B. y RHODES, M. (2005), "EMU and labor market institutions in Europe: the rise and fall of national social pacts", en Work and Occupations, vol.32, n 2, pp.196-228.

HASSEL, A. (2008), "Policies and politics in social pacts in Europe", en European Journal of Industrial Relations, vol.15, $\mathrm{n}^{\mathrm{o}} 1$, pp.1-25.

HOWELL, C. y GIVAN, R. K. (2011), "Rethinking institutions and institutional change in European industrial relations" en British Journal of Industrial Relations, vol.49, n 2, pp. 231-255.

KÖHLER, H-D. y MARTÍN ARTILES, A. (2010), Manual de la Sociología del Trabajo y de las Relaciones Laborales, Madrid, Delta.

MOLINA, O. y RHODES, M. (2011), "Spain: from tripartite to bipartite pacts", en Avdagic, S.; Rhodes, M. y Visser, J. (eds.), Social pacts in Europe. Emergence, evolution, and institutonalization. Oxford, Oxford University Press, pp.174-202.

NATALI, D. y POCHET, P. (2009), "The evolution of social pacts in the EMU era: what type of institutionalization?", en European Journal of Industrial Relations, vol.15, n 2, pp.147-166.

NATALI, D. y POCHET, P. (2010), "Introduction. The last wave of social pacts in Europe: problems, actors and institutions", en D. Natali; M. Keune y P. Pochet (eds.), After the euro and enlargement: social pacts in the EU, Bruselas, ETUI \& OSE.

NONELL, R. (1987), "Estructuras de concertación económica: una aproximación metodológico conceptuar", en Cuadernos de Economía, vol.15, n 43, pp.269-288.

NONELL, R.; MEDINA, I. y MOLINS, J.M. (2011), "Social pacts and the institutionalisation of social actors in Spain. The case of employers associations", en M. Baglioni y B. Brandl (eds). Changing labour relations between path dependency and global trends, Frankfurt, Peter Lang.

ROYO, S. (2007), "Beyond confrontation: The resurgence of social bargaining in Spain in the 1990s", en Comparative Political Studies, vol.39, nº 8, pp.969-995.

SCHMITTER, Ph. (2008), "The changing politics of organised interests", en West European Politics, vol.31, no $1-2$, pp.195-210.

SIEGEL, N.A. (2005), "Social pacts revisited: "Competitive concertation" and complex causality in negotiated welfare state reforms", en European Journal of Industrial Relations, vol.11, n 1, pp.107126.

WINDMULLER, J.P. (1989), Nueva consideración de la negociación colectiva en los países industrializados, Madrid, MTAS. 


\title{
Breve currículo
}

\author{
Iván Medina Iborra \\ Becario Postdoctoral, Departamento de Ciencia Política y Relaciones Internacionales. Doctor en Ciencia \\ Política por la Universidad Autónoma de Barcelona (2012). Actualmente realiza una estancia de \\ investigación postdoctoral en la Universidad Autónoma de Madrid bajo el programa Alianza 4 \\ Universidades. Ha realizado estancias de investigación en las Universidades de Granada, Valencia, \\ Edimburgo y West of England (Bristol). Sus principales líneas de investigación incluyen: a) grupos de \\ interés, b) regionalismo, y c) relaciones laborales y pactos sociales.
}

\section{Joaquim M. Molins}

Doctor en Derecho por la Universidad de Barcelona y Catedrático de Ciencia Política en la Universidad Autónoma de Barcelona. Cuenta con una destacada trayectoria académica centrada en grupos de interés y comportamiento electoral. Ha realizado estancias de investigación en las universidades de Michigan, Yale y Florencia, así como dirigido varias tesis y trabajos de investigación sobre organizaciones empresariales y partidos políticos. Actualmente es investigador principal en investigaciones sobre regiones y organizaciones empresariales (Ministerio de Ciencia e Innovación, CSO2009-13647) y sobre las relaciones de poder entre elites políticas y elites económicas a nivel local (PR2010-0351).

\section{Carmen Navarro Gómez}

Doctora en Derecho por la Universidad de Alcalá de Henares. Profesora contratada doctora de Ciencia Política y de la Administración. Directora del Departamento de Ciencia Política y Relaciones Internacionales, Facultad de Derecho. Universidad Autónoma de Madrid. Cuenta con una destacada trayectoria académica centrada en las políticas públicas en general, en especial locales y del medioambiente. Ha realizado estancias de investigación en las universidades de Georgetown Public Policy Institute, Boston College, Department of Political Science, Centre d'Etude et Recherche sur la Vie Local (CERVL). Sciences Po, Bordeaux. Así como ha dirigido varias tesis y trabajos de investigación sobre el gobierno local, la implementación y evaluación de las políticas públicas. 